\title{
NOTICIARIO
}

\section{Apuntes en torno al uso de los arpones magdalenienses: primeras observaciones microscópicas a partir de los materiales de El Horno (Ramales de la Victoria, Cantabria)}

\author{
Notes around the Magdalenian harpoons: first microscopic observations on the materials \\ from El Horno (Ramales de la Victoria, Cantabria)
}

\author{
Miguel A. Fano (*) \\ Ignacio Clemente $(* *)$ \\ Olivia Rivero (***)
}

\section{RESUMEN}

Se presenta el análisis microscópico de tres arpones magdalenienses procedentes de la cueva de El Horno (Ramales, Cantabria). Su fin era la identificación, en superficie, de rastros susceptibles de aportar información preliminar sobre el uso de los arpones. Las observaciones sobre uno de ellos revelan que se empleó en distintas ocasiones, quizá para la captura de presas con una piel más resistente que la de los peces. Las trazas identificadas en los otros dos son compatibles con el empleo de cuerdas como parte del dispositivo de enmangue. Los resultados se enmarcan en el debate abierto acerca de la función concreta de los arpones, sin obviar la relación existente entre estas armas y la fauna, otro de los aspectos clave para poder avanzar en el debate. Los test estadísticos efectuados a partir de la información disponible en la costa cantábrica revelan que los arpones magdalenienses no se asocian a ningún tipo de fauna en concreto.

(*) Área de Prehistoria, Dpto. de Ciencias Humanas, Universidad de La Rioja. C/ Luis de Ulloa s/n. 26004 Logroño. España. Correo-e: miguel-angel.fano@unirioja.es

(**) Dpto. de Arqueología y Antropología, Instituto Milá y Fontanals-CSIC. C/ Egípciaques 15. 08001 Barcelona. España. Correo-e: ignacio@imf.csic.es

(***) Centre de Recherche et d'Etudes pour l'Art Préhistorique "Émile Cartailhac", CREAP. TRACES-UMR 5608. Université de Toulouse-Le Mirail - Maison de la Recherche. 5, allée Antonio Machado. 31058 Toulouse Cedex 09. Francia. Correo-e: oliviariver@hotmail.com

Recibido: 28-VI-2012; aceptado: 10-X-2012.

\begin{abstract}
Three Magdalenian harpoons from El Horno Cave (Ramales, Cantabria) have been studied microscopically. The objective of the study was to identify marks on the surface of the harpoons susceptible of providing preliminary information about how they were used. In one case, the observations reveal that the harpoon was used on several occasions, perhaps to capture prey with a tougher skin than that of fish. The marks seen on the other two harpoons are compatible with the use of cord as part of the hafting meth$o d$. We assess these observations within the current debate on the exact purpose of the harpoons, without disregarding the relationship between these weapons and fauna, another of the key points to be able to move forward in the debate. Statistical tests carried out with information available in Cantabrian Spain reveal that Magdalenian harpoons are not associated with any particular type of fauna.
\end{abstract}

Palabras clave: Arpones; Caza; Pesca; Traceología; Análisis microscópico; Estadística; Región Cantábrica; Península Ibérica; Paleolítico Superior-Final; Magdaleniense.

Key words: Harpoons; Hunting; Fishing; Use wear analysis; Microscopic study; Statistics; Cantabrian Spain; Iberian Peninsula; Upper-Late Palaeolithic; Magdalenian.

\section{INTRODUCCIÓN}

El arpón ha sido, desde los albores de la investigación, una pieza clave en el establecimiento 
de la cronología relativa del final del Paleolítico (Breuil 1912). En la costa cantábrica, la presencia y morfología de los arpones siguen constituyendo criterios clave para la delimitación y subdivisión del Magdaleniense reciente. No se consideran ya elementos definitorios desde el punto de vista cultural, pero ayudan a delimitar y parcelar esa etapa del final del Paleolítico (González Sainz y González Urquijo 2007).

La adición de dientes a las puntas elaboradas sobre materias duras animales fue una innovación de gran calado de estas armas, que supuso un cambio importante en la concepción de la captura de las presas. Ha podido comprobarse experimentalmente (Pokines y Krupa 1997) que, gracias al diseño de los dientes, las puntas no se desprenden fácilmente de las presas heridas. El nuevo modus operandi no supuso la desaparición del armamento tradicional (azagayas). Su introducción pudo ser una respuesta a nuevas necesidades o quizá simplemente un modo de incrementar la eficacia del armamento empleado para determinadas capturas.

La novedad parece documentarse por primera vez en el registro africano de la Middle Stone Age (Yellen et al. 1995), aunque la antigüedad de los materiales de Katanda (Zaire) no ha estado exenta de debate ( $c f$. Klein 1999: 439; McBrearty y Brooks 2000). Aquí estudiamos arpones mucho más recientes, en torno a 13000 BP (14000 cal BC), cuando, tras una fase caracterizada por la amplia variabilidad formal de los llamados "protoarpones", comienzan a manufacturarse en la región cantábrica armas con formas estandarizadas. La distribución geográfica de los arpones magdalenienses abarca buena parte de Europa occidental, aunque la mayoría se concentra en el Norte de la Península Ibérica y el Sur de Francia (Julien 1995).

Los interrogantes acerca de su función concreta existen desde los albores de la investigación. El tema se abordó directamente en los trabajos de referencia sobre este morfotipo (Julien 1982; Weniger 1995). El debate continúa abierto, aunque no faltan algunos acuerdos. Quizá el más importante sea asumir nuestro conocimiento parcial del utillaje estudiado, por otro lado, un lugar común cuando nos referimos a útiles compuestos prehistóricos de los que solo se han conservado las puntas. El consenso comentado provocó otro: el recurso a la información etnográfica y etnohistórica para visualizar cómo pudo ser el arma completa y cómo y para qué pudo utilizarse -véase la información sobre Tierra del Fuego recientemente publicada (Estévez y Vila 2013)-. Los desacuerdos son sin embargo notables, afectando incluso a la propia denominación de las piezas. M. Julien (1982) o C. González Sainz (1989), p. ej., asumen sin dificultad el término "arpón", mientras que otros como G. C. Weniger (1995) y J. M. Pétillon (2008a) son partidarios del de barbed points, más neutro en relación con el posible uso de estos instrumentos. En este trabajo empleamos el término clásico, pero asumiendo que una parte de los arpones magdalenienses pudo emplearse de un modo y con un fin distinto al que tradicionalmente se les atribuye.

Esencialmente se ha buscado una respuesta a la pregunta sobre el uso de los arpones en la evidencia arqueozoológica, la morfología de las piezas recuperadas y la información relativa a las sociedades subactuales de cazadores. La combinación de datos producto de ese tipo de observaciones ha posibilitado las distintas propuestas que veremos. Pretendemos aportar nuevos datos a la discusión apuntada e insistir en el desarrollo de nuevas líneas de trabajo que permitan formular hipótesis funcionales más sólidas sobre los arpones. Para ello incorporamos el análisis microscópico, todavía con escasas aplicaciones en relación a este tipo de armas (Campana 1989; Buc y Loponte 2007). Tras presentar los materiales estudiados de la cueva de El Horno (Fig. 1) y su contexto arqueológico, detallamos la metodología aplicada y las observaciones realizadas. Antes de valorar los nuevos datos en el marco del debate acerca del uso de los arpones, actualizamos y discutimos la información sobre la relación fauna/arpones, dado que se trata de uno de los aspectos clave para enfrentar la cuestión que nos ocupa, en la región cantábrica en general y en El Horno en particular.

\section{MATERIALES Y MÉTODOS}

El análisis microscópico se ha llevado a cabo en tres fragmentos de arpón sobre asta, procedentes de la campaña de excavación de 2000 en la cueva de El Horno (Ramales, Cantabria). Actualmente están depositados en el Museo de Prehistoria y Arqueología de Cantabria (Fig. 2): 1 núm. inventario M33.32.1; 2 núm. inventario N33.53.4; 3 núm. inventario N33.45.14. 

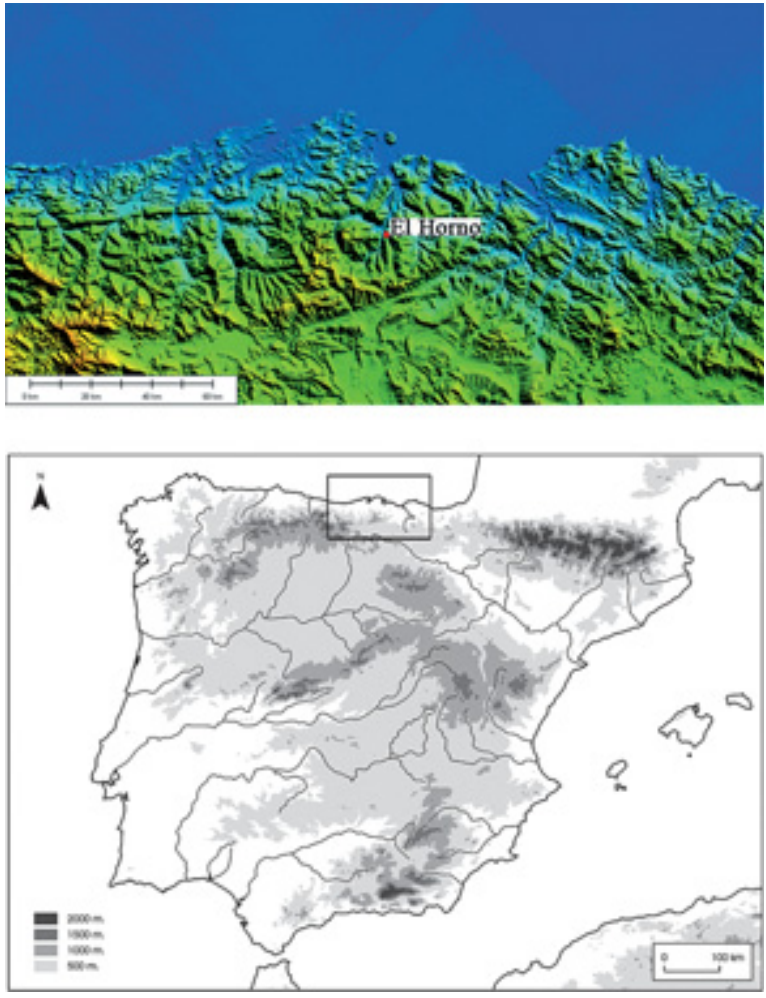

Fig. 1. Localización de la cueva de El Horno (Ramales de la Victoria, Cantabria). Base cartográfica: SRTM Worldwide Elevation data (3arc-second resolution).

Entre 1999 y 2007 se hicieron seis campañas de excavación en El Horno, sobre una superficie de $3,5 \mathrm{~m}^{2}$ (Fano 2005, 2008). Tras la campaña de 2001, se definió en el perfil Oeste del cuadro N32 la siguiente estratigrafía, de muro a techo: nivel 3 , de escasa potencia $(0,05 \mathrm{~m})$ compuesto por un sedimento amarillento de textura arenosa, con escaso material; nivel 2, de 0,23 $\mathrm{m}$ de potencia, con sedimento de color marrón, muy rico en materia orgánica y con abundante material arqueológico; nivel 1, compuesto por un sedimento amarillento de textura compacta, con un espesor de $0,22 \mathrm{~m}$; nivel 0 , con un espesor que oscila entre 0,50 y $0,70 \mathrm{~m}$, interpretado como un revuelto prehistórico, con una matriz variable y materiales arqueológicos de distintos períodos; nivel superficial de $0,10 \mathrm{~m}$ de espesor medio, con una mezcla de materiales modernos y prehistóricos.

Los arpones núm. 1 y 2 analizados proceden del nivel 2, atribuido al Magdaleniense SuperiorFinal (MSF) por incorporar utillaje óseo y lítico compatible con esa atribución. Una muestra de

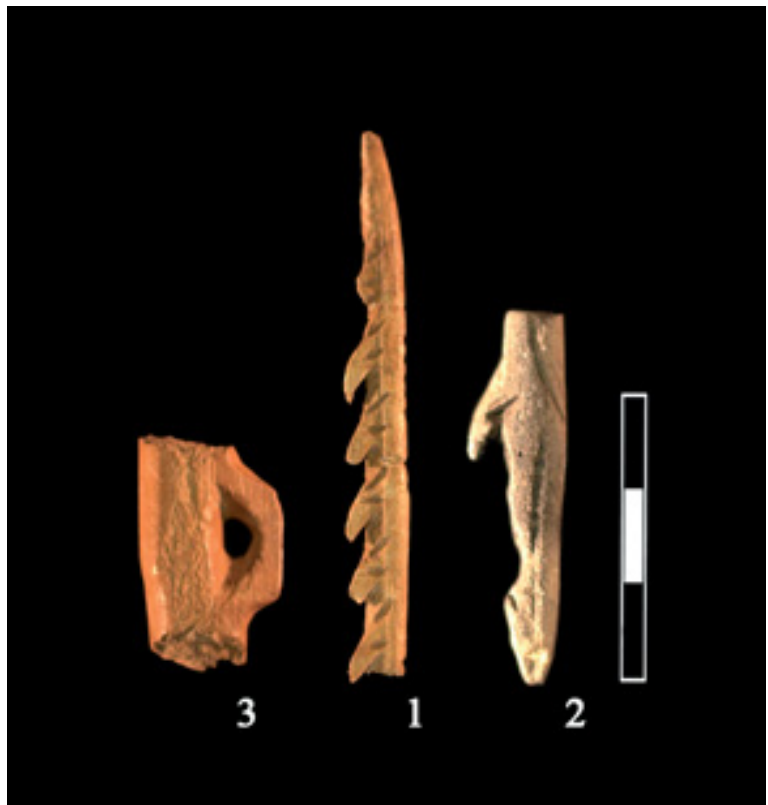

Fig. 2. Arpones de El Horno (Ramales de la Victoria, Cantabria) estudiados: 1 y 2, nivel 2, Magdaleniense Superior-Final; 3, nivel 0, Magdaleniense Superior.

huesos procedentes de la parte superior del nivel proporcionó la datación radiocarbónica GX$27456(12250 \pm 190 \mathrm{BP}, 12481 \pm 424$ cal BC -curva CalPal 2007_HULU, programa CalPal, Weninger et al. 2007). El arpón núm. 3 procede del nivel 0 , donde hay otras piezas especialmente diagnósticas del Magdaleniense Superior.

Como la tipología y decoración de los arpones ya fueron analizadas (Fano et al. 2005), aquí solo apuntamos las características esenciales de los objetos. El núm. 1 es un fragmento meso-distal de un arpón unilateral decorado de sección subcircular. Objetos análogos han sido hallados en otros yacimientos magdalenienses de la región cantábrica, como La Chora y El Valle (González Echegaray et al. 1963: 35; García-Gelabert y Talavera 2004), y del suroeste de Francia, como Isturitz o La Madeleine (Julien 1982: 222, 225 y 226).

El núm. 2 es un fragmento proximal de arpón de sección oval afectado por fuego. Conserva un diente y una decoración similar a la del anterior. La solución adoptada para el enmangue es poco frecuente entre los arpones magdalenienses: una entalladura producto de la reducción del diámetro del fuste. Solo un ejemplar de Morín presenta una morfología similar (González Sainz 1989: 82). 
El núm. 3 es una base perforada de arpón de sección cuadrangular. La perforación se ha realizado sobre una protuberancia lateral alargada y rebajada en grosor con relación al fuste. Este rasgo técnico y morfológico, distintivo de la región cantábrica (Julien 1982: 74), puede observarse en un buen número de ejemplares procedentes de niveles del Magdaleniense avanzado como los de La Pila o Llonín (Bernaldo de Quirós et al. 1992; Fortea et al. 1995), entre otros.

El análisis microscópico de los arpones intentó identificar rastros en las superficies que nos informaran acerca de su posible uso. Las llamadas "fracturas de impacto", junto con abrasiones y estrías microscópicas, son las trazas que se han considerado más significativas para determinar el uso de las puntas de flecha líticas (Fischer et al. 1984; Dockall 1997; Palomo y Gibaja 2003, entre otros). En proyectiles elaborados sobre materias duras animales, esencialmente hueso y asta, también se han identificado distintos tipos de fracturas a nivel arqueológico y experimental (Stodiek 2000; Pétillon 2006, 2008b). Al emplearse como proyectiles de caza, su contacto con otras materias es muy breve y limitado a cuando penetran en la presa. No da tiempo a que se formen rastros específicos en sus superficies. En cambio, las de los instrumentos óseos utilizados para cortar o raspar piel, madera, corteza, etc. sí muestran rastros característicos de la materia trabajada (Semenov 1964; LeMoine 1997; Clemente et al. 2002; Clemente y Gyria 2003; Maigrot 2003, entre otros). A los problemas mencionados hay que unir la falta de estudios experimentales relativos al uso de los arpones. Por todo ello, nuestra lectura de las observaciones microscópicas tendrá, necesariamente, un carácter preliminar.

Hemos identificado y registrado los macro-rastros mediante una lupa estereoscópica, equipada con doble cámara digital, Leica MZ16A, y los micro-rastros mediante un microscopio metalográfico Leica DM2500M con cámara digital DFC420. En ambos casos se ha empleado un software multifocal que agrupa varias imágenes en una sola, que resulta enfocada en toda la profundidad de campo.

\section{OBSERVACIONES REALIZADAS}

El arpón núm. 1 tiene una conservación media con corticalidad en el $70 \%$ de la superficie. Esta se encuentra en buen estado y brilla debido a un micropulido de trama cerrada-compacta, con estrías microscópicas orientadas en diversas direcciones (Fig. 3B). El aspecto superficial es producto, probablemente, de la interacción combinada de variables tecnológicas -raspado con ligero pulido- y taxonómicas - contacto con los sedimentos y manipulación antrópica (pretérita y actual). En especial en la zona opuesta a los dientes del arpón, se observan estrías tecnológicas longitudinales de raspado.

El ápice distal presenta una fractura funcional de impacto que se refleja hacia uno de los laterales. Al desprenderse ha formado un surco ancho y profundo (Fig. 3A). Las aristas y la superficie rugosa de la fractura sufrieron alteraciones con posterioridad (Fig. 3A'), orientadas hacia la propia punta. Se trata de un redondeamiento acentuado, con una orientación paralela al eje longitudinal de la pieza y de estrías cortas y profundas superficiales en la fractura (Fig. 3A'). Estas observaciones son compatibles con un uso del arpón tras la fractura de impacto comentada.

Las fracturas planas en los ápices de los dientes también constituyen un dato relevante.

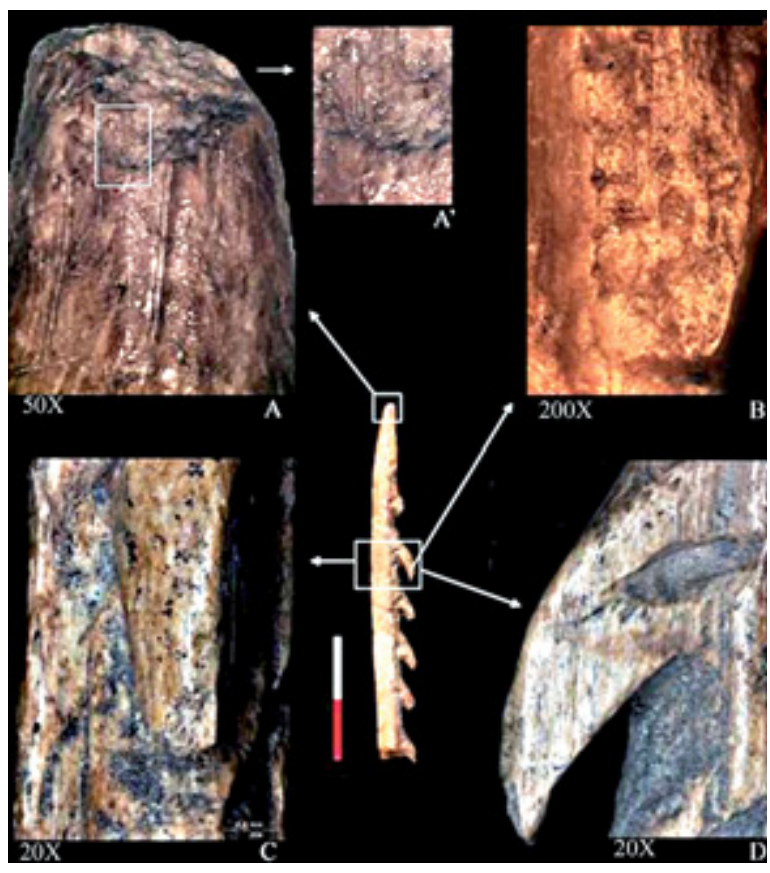

Fig. 3. Arpón núm. 1 de El Horno (Ramales de la Victoria, Cantabria), Magdaleniense Superior-Final. Detalles macro y microscópicos de rastros longitudinales y fractura funcional de impacto (A, A'). 
En dos de ellos hay una fractura corta y plana, con una orientación de extracción contraria a la acción de impacto y penetración (Fig. 3C, D). A la espera de una experimentación que lo corrobore, lo indicado pudo ser consecuencia de la recuperación de la punta del cuerpo de la presa. Al efectuar esta acción, la masa del cuerpo del animal ofrece resistencia a la extracción de los dientes, la parte más débil de la punta, y pudo provocar esos levantamientos orientados hacia ella.

La conservación de la superficie del arpón núm. 2 es peor, dado que ha sido claramente afectada por fuego. Tiene un tipo de fractura que sin permitir considerarla de impacto, tampoco cabe descartarlo. Durante el proceso de análisis se identificó en el extremo distal, hasta el espolón, solo un raspado longitudinal (Fig. 4C) que, como en el caso anterior, reconocemos como un efecto de la técnica de elaboración. La parte central de la pieza, sinuosa por la concavidad y convexidad contiguas, muestra unos evidentes rastros tecnológicos del desbastado de la materia por raspado (Fig. 4B). Sin embargo, al observar la superficie a más aumentos (Fig. 4A), comprobamos que el redondeamiento de todas las zonas elevadas inter-surcos, producto del raspado, es distinto al reconocido en la pieza anterior: ahora incluye pequeños surcos y estrías cuya orientación es contraria o perpendicular al estriado de manufactura. Dichas alteraciones, que solo vemos en esa zona del arpón -compárense por ejemplo las imágenes $4 \mathrm{~A}$ y $4 \mathrm{C}$-, podrían ser consecuencia del contacto de su superficie con algún tipo de cuerda, de origen vegetal o animal, empleada para enmangarlo.

El arpón núm. 3 se conserva mal. En buena parte de la superficie se percibe ya la parte esponjosa del asta sin rastros tecnológicos, ni del posible uso. La observación macro y microscópica de la superficie revela que su técnica de elaboración fue el raspado. Al tiempo, las incisiones reconocidas son compatibles con el empleo de un útil cortante para la perforación (Fig. 5). Su superficie interna y externa muestra un fuerte redondeamiento que, a más aumentos, se comprueba producido por un pulimento con estrías orientadas. Todo ello cabe relacionarlo con el contacto de esa superficie con una cuerda que formaría parte del enmangue del arpón. En la parte opuesta a la perforación, rastros como una superficie con pulido brillante -con mi-

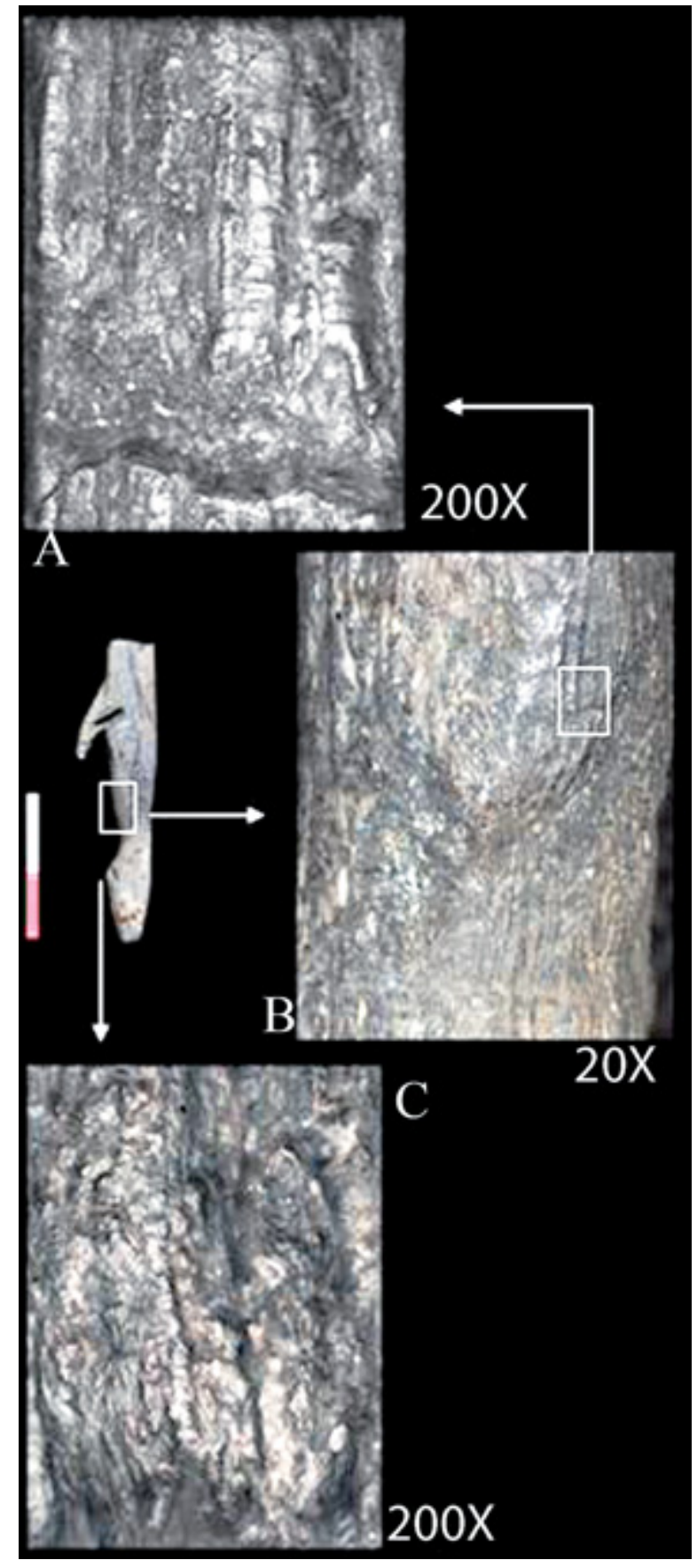

Fig. 4. Arpón núm. 2 de El Horno (Ramales de la Victoria, Cantabria), Magdaleniense Superior-Final, afectado por fuego. Detalles macro y microscópicos de rastros longitudinales $\mathrm{y}$, en $\mathrm{A}$, transversales relacionables con el enmangue.

croagujeros circulares- y estrías orientadas hacia el orificio quizá también estarían relacionadas con

Trab. Prehist., 70, N. ${ }^{\text {2 }}$ 2, julio-diciembre 2013, pp. 332-345, ISSN: 0082-5638

doi: $10.3989 /$ tp.2013.12116 


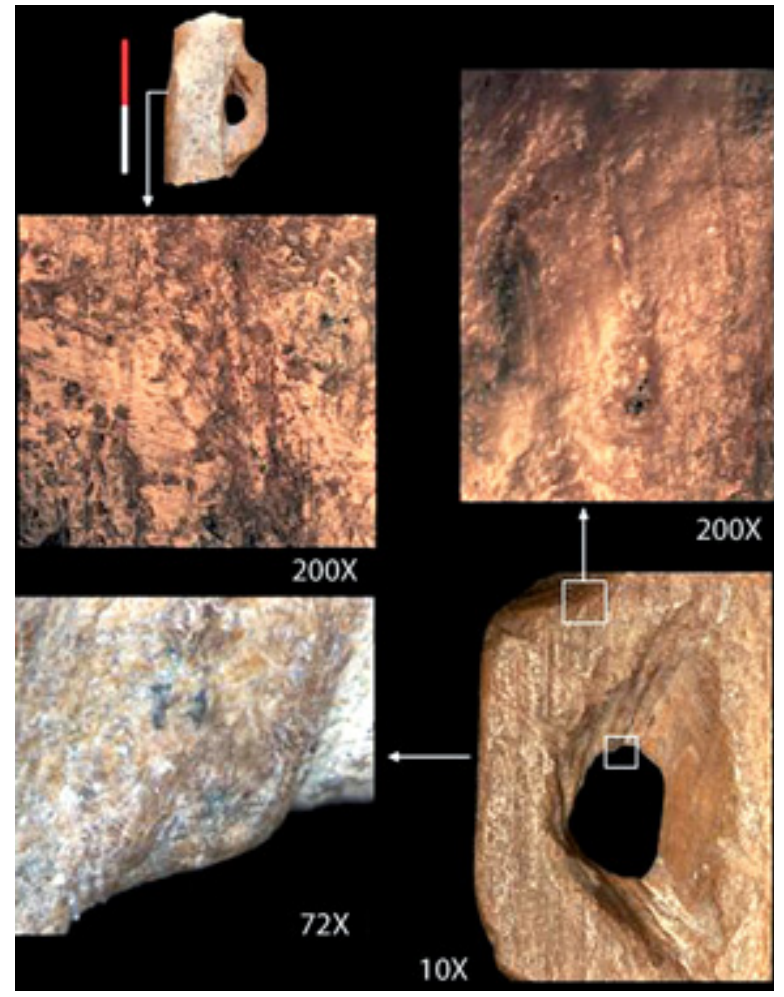

Fig. 5. Arpón núm. 3 de El Horno (Ramales de la Victoria, Cantabria), Magdaleniense Superior-Final. Detalles macro y microscópicos de las incisiones de corte en la perforación y pulimento con estrías orientadas, relacionables con el enmangue.

la atadura. Como en el arpón núm. 2, la hipótesis de enmangue sugerida a partir de la observación microscópica queda pendiente de confirmación experimental.

En síntesis, la observación microscópica ha revelado la conservación de trazas relacionadas con el uso de los arpones. El estudio no solo muestra el empleo del núm. 1 en algún tipo de actividad cinegética, sino que la observación de las aristas de la fractura y de su propia superficie sugiere un uso recurrente del mismo. Las trazas advertidas, ahora a través del microscopio, en las bases de los arpones núm. 2 y 3 resultan en principio compatibles con el empleo de cuerdas para su enmangue.

A continuación, enmarcamos nuestros comentarios en el debate sobre el uso de los arpones, sin obviar, tal y como apuntamos en la introducción, la relación fauna/arpones, aspecto clave para avanzar en dicha discusión.

\section{DISCUSIÓN}

La morfología de los arpones, y ciertas observaciones a nivel macroscópico, han tenido un peso esencial en las propuestas relativas a su uso en detrimento de otros enfoques como el análisis microscópico o la experimentación. El empleo de astiles se ha deducido de la morfología de las bases de los arpones, en ocasiones con huellas producidas por el contacto con el astil. Ciertos rastros evidenciarían el empleo de cordajes, al tiempo que las perforaciones o los abultamientos laterales estarían vinculados a la fijación de dichos cordajes, o con otros aspectos relacionados con el óptimo funcionamiento del arma (Barandiarán 1973: 64; Julien 1982: 138; Múgica 1983: 522; González Sainz 1989; Weniger 2000; Julien y Orliac 2003; Villaverde y Román 2005/06; Román y Villaverde 2011; Estévez y Vila 2013).

Las observaciones relativas a la morfología de las piezas y la analogía etnográfica, condujeron inicialmente a Julien (1982) a decantarse por un empleo preferente de los arpones en medios acuáticos, que incluía la captura de los animales terrestres que los transitaran. La continuidad de las azagayas se adujo como prueba indirecta de esa tesis: se habría producido una complementariedad entre armas indicadas para la caza en diferentes medios. Al tiempo, Julien vinculó la variabilidad morfológica de los arpones a diferencias de índole funcional. Habría ejemplares destinados a la captura de peces de tamaño considerable, como el salmón, y otros de menor tamaño diseñados para la pesca de especies de menor talla y que frecuentan aguas poco profundas, como el lucio y la trucha, o destinados a otro sistema de lanzamiento, como el arco. Otros autores recurrieron a esa idea para plantear el uso hipotético de los arpones, en áreas como la costa mediterránea peninsular (Cacho et al. 2001).

Con posterioridad, la presencia de ranuras en la zona mesial de ejemplares unilaterales de La Vache, quizá destinadas a alojar armaduras de sílex, modificó la perspectiva de Julien (1999): en el caso de que esas armas las portaran, como algunas azagayas de sitios como Pincevent o Saint Marcel, sí estarían específicamente indicadas para la captura de fauna terrestre. Previamente, Weniger $(1992,1995,2000)$ ya había cuestionado la identificación como arpones del conjunto de piezas magdalenienses. Este autor comparó el 
material arqueológico con más de 300 armas conservadas en distintos museos y procedentes de varios contextos etnohistóricos de Norteamérica, distinguiendo categorías funcionales en las piezas magdalenienses a partir de sus atributos morfológicos. Según Weniger, todas las categorías pudieron emplearse para capturar peces, pero dos de ellas además para la caza en el medio terrestre.

Pétillon (2008a) ha abogado por vincular la definición de los arpones con su modus operan$d i$, es decir, instrumentos que incluyen una punta diseñada para permanecer alojada en la presa para lo que cuentan con un sistema de retención, y no tanto con sus características morfológicas o estructurales. En su amplia revisión de la literatura etnográfica -correspondiente a 22 sociedades de cazadores-recolectores de Norteamérica y, donde, a diferencia de Julien, valoró todos los tipos de barbed points - comprobó cómo los instrumentos que responden a ese modus operandi no siempre incluyen una punta móvil o una cuerda (véase también al respecto Estévez y Vila 2013: 295).

Otras observaciones de este autor corroboran la imposibilidad de interpretar el material magdaleniense en base a criterios exclusivamente morfológicos, y pueden favorecer un análisis más crítico del empleo de esos objetos: por ejemplo, la presencia de una o dos protuberancias laterales en la base de un objeto no garantiza que se trate de un arpón. En puntas empleadas para cazar alces que no responden al modus operandi apuntado, la función de la protuberancia lateral difiere de la registrada en los arpones. Del mismo modo, que haya una perforación lateral -como en las "bases de tipo cantábrico"- tampoco nos asegura que la punta sea un arpón, dado que la literatura etnográfica documenta piezas con bases muy similares pero usadas para fines tan distintos como la pesca y la guerra.

En síntesis, nos movemos en un escenario de gran complejidad, en el que la lista de posibles usos de los arpones magdalenienses es mayor que la inicialmente imaginada (Pétillon 2008a). Como apunta Pétillon, para avanzar en la asignación funcional será necesario insistir en aspectos como la relación fauna/arpones o la evidencia etnográfica -considerando contextos como los de las costas del Pacífico- y sin obviar las posibilidades que ofrece la experimentación, tal y como se ha comprobado con otro tipo de armas (Pétillon 2006).
En la costa cantábrica y mediterránea, el vínculo entre la introducción de los arpones y el incremento de los restos ictiológicos es un lugar común en la bibliografía (González Sainz 1989; (1); Cacho y de la Torre 2005). En cambio, en el registro francés, hace un par de décadas J. J. Cleyet-Merle (1990: 81) mostró su escepticismo respecto a considerar los arpones como instrumentos de pesca. Recientemente Pétillon (2008a) no ha constatado, en la vertiente norte de los Pirineos, una relación entre las armas estudiadas y un tipo concreto de fauna, pero la muestra tiene serias limitaciones. Otros contextos, como el nivel 5 de Bois-Ragot (Vienne) (Chollet y Dujardin 2005), sí revelan un nexo significativo. Incluye un alto porcentaje de arpones asociado a una fauna de pequeña talla: pájaros y liebre ártica, pero las pequeñas dimensiones de la ictiofauna recuperada se relacionan más con el empleo de instrumentos como trampas, nasas o redes (cf. Cravinho y Desse-Berset 2005: 370). En cualquier caso, no faltan en la bibliografía francesa referencias explícitas a la relación pesca/arpones (Le Gall 2003).

Hemos compilado la información disponible en la región cantábrica durante el MSF tanto sobre los arpones como sobre los restos faunísticos (ictiofauna incluida) para contar con una base documental, análoga a la de J. M. Pétillon (2008a) para los Pirineos, que nos permitiera abordar su problemática funcional. La primera dificultad reside en la calidad y la cantidad de los datos disponibles, muy desigual según los yacimientos. Ello se debe, en gran medida, a la frágil naturaleza de los restos ictiológicos que hace compleja su recuperación, en particular en las excavaciones antiguas. De este modo, la baja resolución de la información disponible no aporta argumentos sólidos a la discusión sobre el empleo de los arpones ni sobre el incremento de los restos ictiológicos durante el MSF. Por añadidura, se hace necesaria una comparación con los niveles del Magdaleniense, Medio o Inferior, en aquellos sitios con continuidad estratigráfica a lo largo del Magdaleniense, destinada a considerar con mayor seguridad si la aparición de los arpones conlleva diferencias en el espectro faunístico recuperado.

(1) Fernández, R. 2001: La actividad pesquera en la región cantábrica durante el Paleolítico y el Epipaleolítico. Estado de la cuestión. Trabajo de investigación de tercer ciclo inédito. Universidad de Cantabria. Santander.

Trab. Prehist., 70, N. ${ }^{\circ}$ 2, julio-diciembre 2013, pp. 332-345, ISSN: 0082-5638

doi: $10.3989 /$ tp.2013.12116 
Una valoración preliminar de los datos procedentes de 63 niveles del Magdaleniense cantábrico, cuya calidad informativa es suficiente, permite apuntar, con reservas, hechos que dejan entrever una situación más compleja de lo que podría pensarse en principio. La incorporación de los arpones no parece conllevar la explotación de nuevas especies de ungulados, o un cambio significativo en la proporción de las tradicionalmente abatidas. La variación consiste en la aparición marginal de Sus scrofa en el espectro, relacionada más bien con los cambios paleoclimáticos, o en el aumento de Equus con respecto a niveles de momentos anteriores (Tab. 1, pie en página siguiente).

\begin{tabular}{|c|c|c|c|c|c|c|c|c|c|c|c|c|c|c|c|c|c|c|c|}
\hline \multirow[b]{2}{*}{ Yacimiento (Bibliografía) } & \multirow[b]{2}{*}{ Etapa } & \multicolumn{3}{|c|}{ Cervus } & \multirow{2}{*}{\begin{tabular}{|c|} 
Bos \\
$\mathrm{E}$
\end{tabular}} & \multicolumn{2}{|c|}{ Equus } & \multicolumn{3}{|c|}{ Capra } & \multicolumn{2}{|c|}{ Rupicapra } & \multicolumn{2}{|c|}{ Capreolus } & \multirow{2}{*}{\begin{tabular}{|c|} 
Rangifer \\
E \\
\end{tabular}} & \multirow{2}{*}{$\begin{array}{c}\text { Sus } \\
\mathrm{E} \\
\end{array}$} & \multicolumn{2}{|c|}{$\begin{array}{c}\text { Ictiofauna } \\
\text { fluvial }\end{array}$} & \multirow{2}{*}{$\begin{array}{c}\begin{array}{c}\text { Ictiofauna } \\
\text { marina }\end{array} \\
\mathrm{E} \\
\end{array}$} \\
\hline & & MF & FM & $\mathrm{E}$ & & FM & E & MF & FM & $\mathrm{E}$ & FM & E & FM & E & & & $\mathrm{F}$ & E & \\
\hline La Paloma 6 (1) & MM & - & & & - & & $\cdot$ & & & - & & $\cdot$ & & $\cdot$ & - & & & & \\
\hline La Paloma 4 (2) & MSF & - & & & $\cdot$ & & • & & & · & & $\cdot$ & & & & & & $\cdot$ & \\
\hline Sofoxó (3) & MSF & & $\cdot$ & & $\cdot$ & & $\cdot$ & & - & & & $\cdot$ & & $\cdot$ & & - & & $\cdot$ & \\
\hline Las Caldas V (4) & MM & & - & & & & $\cdot$ & & - & & - & & - & & & & & - & \\
\hline Las Caldas IV (5) & MM & & $\cdot$ & & $\cdot$ & & $\cdot$ & & • & & • & & & $\cdot$ & & & & $\cdot$ & \\
\hline Las Caldas III (6) & MM-MSF & & $\cdot$ & & & & $\cdot$ & & - & & $\cdot$ & & & & & & & $\cdot$ & $\cdot$ \\
\hline Las Caldas II (7) & MSF & & & $\cdot$ & & & $\cdot$ & & & - & $\cdot$ & & & $\cdot$ & & & & 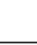 & \\
\hline Cova Rosa A (8) & MSF & & & $\cdot$ & & & & & & $\cdot$ & & & & & & & & & \\
\hline Tito Bustillo la (9) & $\mathrm{M}$ & $\cdot$ & & & $\cdot$ & & $\cdot$ & & & - & & $\cdot$ & & $\cdot$ & & & & $\cdot$ & \\
\hline Tito Bustillo lb (10) & M & $\cdot$ & & & $\cdot$ & & $\cdot$ & & & $\cdot$ & & $\cdot$ & & & • & & $\cdot$ & & $\cdot$ \\
\hline Tito Bustillo 1c (11) & $\mathrm{M}$ & $\cdot$ & & & $\cdot$ & & $\cdot$ & & & - & & $\cdot$ & & & & & & $\cdot$ & \\
\hline Tito Bustillo 2 (12) & $\mathrm{M}$ & $\cdot$ & & & & & & & & - & & $\cdot$ & & & & & & & \\
\hline Coberizas (13) & MI & & & $\cdot$ & & & & & & - & & $\cdot$ & & & & & & • & \\
\hline Cueto de la Mina B (14) & MSF & & $\cdot$ & & $\cdot$ & & $\cdot$ & & $\cdot$ & & & $\cdot$ & & $\cdot$ & $\cdot$ & & & & \\
\hline La Riera 18 (15) & MI & $\cdot$ & & & & & $\cdot$ & & $\cdot$ & & & & & & & & & & \\
\hline La Riera 19 (16) & MI & - & & & & & $\cdot$ & & $\cdot$ & & & $\cdot$ & & $\cdot$ & & & & $\cdot$ & \\
\hline La Riera 20 (17) & MI-MM & $\cdot$ & & & & & $\cdot$ & & - & & & & & $\cdot$ & & & & & \\
\hline La Riera 21-23 (18) & MSF & - & & & & & $\cdot$ & & & - & & 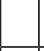 & & $\cdot$ & - & · & & & \\
\hline La Riera 24 (19) & MSF & & $\cdot$ & & & & $\cdot$ & & $\cdot$ & & & $\cdot$ & & $\cdot$ & $\cdot$ & & & $\cdot$ & \\
\hline La Riera $25(20)$ & MSF-AZ & & $\cdot$ & & & & . & & & - & & . & & $\cdot$ & 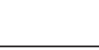 & . & & $\cdot$ & \\
\hline La Riera 26 (21) & MSF-AZ & & $\cdot$ & & & & $\cdot$ & & $\cdot$ & & & $\cdot$ & & $\cdot$ & & $\cdot$ & & $\cdot$ & • \\
\hline Los Canes 2c (22) & MSF & & & $\cdot$ & & & & & $\cdot$ & & & $\cdot$ & & & & & & & \\
\hline Hornos de la Peña (23) & $\mathrm{M}$ & & $\cdot$ & & $\cdot$ & $\cdot$ & & & & - & $\cdot$ & & & & & & & & \\
\hline El Pendo II (24) & MSF & $\cdot$ & & & $\cdot$ & & $\cdot$ & & & - & & $\cdot$ & & $\cdot$ & & $\cdot$ & & & \\
\hline Morín 2 (25) & MSF & - & & & $\cdot$ & & $\cdot$ & & & - & & $\cdot$ & & $\cdot$ & • & · & & & \\
\hline El Rascaño 4b (26) & MI & & & $\cdot$ & & & $\cdot$ & - & & & & & & & & & & & \\
\hline El Rascaño 4a (27) & MI & & & $\cdot$ & • & & $\cdot$ & $\cdot$ & & & & & & & & & & & \\
\hline El Rascaño 3 (28) & MI & & & $\cdot$ & $\cdot$ & & $\cdot$ & $\cdot$ & & & & $\cdot$ & & & & & & $\cdot$ & \\
\hline El Rascaño 2.3 (29) & MSF & & & $\cdot$ & & & $\cdot$ & $\cdot$ & & & & $\cdot$ & & & & • & & • & \\
\hline El Piélago 6 (30) & MSF & & & $\cdot$ & & & & & $\cdot$ & & & $\cdot$ & & & & & & & \\
\hline El Piélago $5 b$ (31) & MSF & & & $\cdot$ & & & & & - & & & $\cdot$ & & & & & & & \\
\hline El Piélago 5a (32) & MSF & & & $\cdot$ & & & & & - & & $\cdot$ & & & & & & & & \\
\hline La Garma L3 (33) & MM & & $\cdot$ & & & $\cdot$ & & & & - & & & & $\cdot$ & • & & & • & \\
\hline
\end{tabular}




\begin{tabular}{|c|c|c|c|c|c|c|c|c|c|c|c|c|c|c|c|c|c|c|c|}
\hline \multirow[b]{2}{*}{ Yacimiento (Bibliografía) } & \multirow[b]{2}{*}{ Etapa } & \multicolumn{3}{|c|}{ Cervus } & \multirow{2}{*}{\begin{tabular}{|c|} 
Bos \\
$\mathrm{E}$
\end{tabular}} & \multicolumn{2}{|c|}{ Equus } & \multicolumn{3}{|c|}{ Capra } & \multicolumn{2}{|c|}{ Rupicapra } & \multicolumn{2}{|c|}{ Capreolus } & \multirow{2}{*}{$\frac{\text { Rangifer }}{\text { E }}$} & \multirow{2}{*}{$\frac{\text { Sus }}{\mathrm{E}}$} & \multicolumn{2}{|c|}{$\begin{array}{c}\text { Ictiofauna } \\
\text { fluvial }\end{array}$} & \multirow{2}{*}{$\begin{array}{c}\begin{array}{c}\text { Ictiofauna } \\
\text { marina }\end{array} \\
\mathrm{E}\end{array}$} \\
\hline & & MF & FM & $\mathrm{E}$ & & FM & $\mathrm{E}$ & MF & FM & E & FM & E & FM & E & & & $\mathrm{F}$ & E & \\
\hline La Garma Gal. Inf. (34) & MM & & & - & - & $\cdot$ & & & & & & & & & - & & & & \\
\hline El Valle (35) & MSF & $\cdot$ & & & & & & & $\cdot$ & & & $\cdot$ & & $\cdot$ & & & & $\cdot$ & \\
\hline El Mirón 12 (36) & MSF & & $\cdot$ & & & & - & & - & & & & & - & & & & & \\
\hline El Mirón 308 (37) & MSF & & • & & & & & & - & & & - & & & & & & & \\
\hline El Mirón 307 (38) & MSF & & - & & & & & & - & & & - & & - & & - & & & \\
\hline El Mirón 106 (39) & MSF & & $\cdot$ & & & & - & & - & & & - & & $\cdot$ & & - & & & \\
\hline El Mirón 105 (40) & MSF & & - & & & & & & - & & & & & & & & & & \\
\hline El Mirón 104 (41) & MSF & & • & & & & - & & - & & & - & & & & & & & \\
\hline El Mirón 103 (42) & MSF & & & - & & & & & & . & & & & & & & & & \\
\hline El Horno 3 (43) & MSF & & & & & & & & & . & & & & & & & & • & \\
\hline El Horno 2 (44) & MSF & & & - & & & . & . & & & & . & & . & & . & . & & \\
\hline El Horno 1 (45) & MSF & & & - & & & $\cdot$ & $\cdot$ & & & & $\cdot$ & & 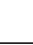 & & . & $\cdot$ & & \\
\hline La Fragua (46) & MSF & & - & & $\cdot$ & & & & - & & & - & & - & & - & & & \\
\hline Atxeta E (47) & MSF & · & & & & & - & & & - & & & & & & & & & \\
\hline Santimamiñe VI (48) & MSF & & - & & $\cdot$ & & - & & & - & & - & & - & - & - & & • & \\
\hline Lezetxiki I (49) & MSF & & & $\cdot$ & $\cdot$ & & • & & & $\cdot$ & & $\cdot$ & & 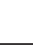 & & $\cdot$ & & & \\
\hline Laminak II (50) & MSF & & - & & - & & - & & & - & & - & & & & - & - & & - \\
\hline Ermittia (51) & M & & & $\cdot$ & $\cdot$ & & • & - & & . & & $\cdot$ & & $\cdot$ & - & $\cdot$ & & • & \\
\hline Urtiaga F (52) & MI & & & $\cdot$ & • & & • & & & • & & • & & . & - & & & & \\
\hline Urtiaga D (53) & MSF & & $\cdot$ & & $\cdot$ & & • & & $\cdot$ & & & $\cdot$ & & $\cdot$ & - & $\cdot$ & & • & \\
\hline Ekain VII (54) & MI & $\cdot$ & & & $\cdot$ & & $\cdot$ & & & · & & $\cdot$ & & $\cdot$ & & & & • & \\
\hline Ekain Vib (55) & MSF & & $\cdot$ & & $\cdot$ & & & & $\cdot$ & & & . & & $\cdot$ & - & & & $\cdot$ & \\
\hline Ekain Via (56) & MSF & & & $\cdot$ & $\cdot$ & & & & - & & & $\cdot$ & & $\cdot$ & & & & • & \\
\hline Ekain V (57) & MSF-AZ & & - & & • & & & & - & & & • & & . & & & & - & \\
\hline Erralla V (58) & MI & & & $\cdot$ & $\cdot$ & & • & • & & & & - & & - & • & & & • & \\
\hline Erralla III-II (59) & MSF & & & $\cdot$ & $\cdot$ & & - & & - & & $\cdot$ & & & - & - & & & - & \\
\hline Aitzbitarte IV (60) & MSF & & $\cdot$ & & $\cdot$ & & $\cdot$ & & & • & - & & & $\cdot$ & • & • & & & \\
\hline Abauntz e (61) & MM & & & - & $\cdot$ & & - & & & - & $\cdot$ & & & & - & & & - & \\
\hline Zatoya Iib (62) & MSF & & - & & $\cdot$ & & • & & & • & & • & & & - & $\cdot$ & & - & \\
\hline Zatoya II (63) & MSF & & - & & - & & - & & & - & & - & & - & & - & & & \\
\hline
\end{tabular}

Tab. 1. Muestra de 63 niveles del Magdaleniense Cantábrico con y sin arpones, y estimación de la fauna. Se indican, mediante punteado, los niveles en los que se hallaron arpones. Ungulados (Número de Restos superior a 30): MF muy frecuente $>80 \%$; FM frecuencia media 20 a 80\%; E escaso < 20\%. Ictiofauna (no porcentual): E escaso; F frecuente. Atribución crono-cultural: M Magdaleniense; MI M Inferior; MM M Medio; MSF M Superior-Final; AZ Aziliense. Bibliografía: 1. Adán 1997. 2. González Sainz 1989; Adán 1997. 3. Adán 1997. 4-5. Corchón et al. 2005. 6. Corchón et al. 2005; Corchón et al. 2008. 7. Corchón 2007. 8. Jordá y Gómez Fuentes 1982. 9-11. González Sainz 1989. 12. Yravedra 2002. 13. Clark 1972; González Morales 1982. 14. Castaños 1982; González Sainz 1989. 15-21. Straus y Clark 1986. 22. Arias y Pérez 1995; Adán 1997; 23. Yravedra 2010. 24-25. González Sainz 1989. $26-29$. González Echegaray y Barandiarán 1981. 30-32. González Sainz 1989. 33 Adán 1997. Fernández 2001. 34. Arias et al. 2011. 35. García Gelabert y Talavera 2004. 36. Straus y González Morales 2003. 37-42. Marín 2009, 2010. 43-45. Fano 2005; Costamagno y Fano 2005. 46. Marín y González Morales 2007. 47. Barandiarán 1960; González Sainz 1989. 48-49. González Sainz 1989. 50. Castaños 1994; Roselló et al. 1994. 51. González Sainz 1989. 52-53. Barandiarán 1967. 54-57. Altuna y Merino 1984. 58-59. Altuna y Mariezkurrena 1985. 60. González Sainz 1989. 61. Altuna y Mariezkurrena 1982. 62-63. Barandiarán y Cava 2001; Altuna y Mariezkurrena 2001. Nota: en el momento en el que se llevó a cabo la recogida de información, no se disponía aún de los datos relativos al MI y MM de El Mirón, así como de la información correspondiente a la reciente revisión del depósito arqueológico de Santimamiñe.

Trab. Prehist., 70, N. ${ }^{\circ} 2$, julio-diciembre 2013, pp. 332-345, ISSN: 0082-5638

doi: $10.3989 /$ tp.2013.12116 
Los niveles del MSF, según los test efectuados sobre un total de 39 (Tab. 2), muestran que la matriz de correlación entre los arpones y la fauna presente (incluida la ictiofauna) es muy pobre, sin superar en ningún caso probabilidades superiores al 60\% (Anexo I). Estos resultados revelan que los arpones magdalenienses de la región cantábrica no se asocian a ningún tipo de fauna en concreto.

Los datos disponibles de fauna en El Horno están en sintonía con el panorama general descrito. De momento los niveles del MSF con y sin arpones conocidos carecen de diferencias significativas en la fauna documentada.

El uso de los arpones como puntas ha quedado verificado por el análisis microscópico aquí presentado. Los comentarios a nivel macroscópico, referidos a las llamadas "fracturas burinantes" producto del empleo de los instrumentos como puntas (Villaverde y Román 2005/06), han podido precisarse gracias a la observación microscópica de la pieza núm. 1. Las fracturas planas identificadas en algunos de sus dientes sugieren la captura de presas con una piel algo más robusta o resistente que la los peces. Ello estaría en sintonía con la posibilidad, planteada por distintos autores, del empleo de los arpones para la captura de fauna terrestre. Sin embargo está pendiente todavía la verificación experimental de las alteraciones que la anatomía de los peces $-\mathrm{y}$ de otras presas potenciales, tanto terrestres como marinas- puede provocar sobre esas armas, máxime cuando nos referimos a capturas de buen tamaño como las de El Horno -truchas de más de $45 \mathrm{~cm}$ (dato $\mathrm{O}$. Le Gall)-

La referencia al empleo de algún tipo de cordaje para enmangar los arpones magdalenienses es un lugar común en la bibliografía (p. ej. González Sainz 1989), sin que falten alusiones a trazas superficiales vinculadas al empleo de cuerdas (Julien y Orliac 2003). En los arpones 2 y 3 las alteraciones advertidas a nivel microscópico son compatibles con él y permiten una mejor comprensión del correspondiente modus operandi. En el núm. 3 con base perforada de tipo cantábrico, los resultados apoyan el empleo de las perforaciones para alojar un cordaje que permitiese recuperar la punta y tomar la presa (Pétillon 2008a). El extremo proximal, hasta el espolón, del núm. 2 pudo estar insertado en un astil o en una pieza intermedia. Más difícil resulta pronunciarse, al menos de momento, acerca del tipo de presas capturadas.

\begin{tabular}{lc}
\hline \multicolumn{1}{c}{ Niveles con fauna y arpones } & \% de correlación \\
\hline Equus escaso & 60 \\
Sus escaso & 54 \\
Cervus muy frecuente & 43 \\
Rupicapra escaso & 38 \\
Ictiofauna frecuente & 35 \\
Capreolus escaso & 31 \\
Bos escaso & 29 \\
Ictiofauna escaso & 26 \\
Capra escaso & 23 \\
Rangifer escaso & 18 \\
Rupicapra medio & 12 \\
\hline
\end{tabular}

Tab. 2. Test de la desviación reducida o Z-score (Ley de Laplace-Gauss) aplicado a una muestra de 39 niveles del Magdaleniense Superior-Final de la región cantábrica, con arpones y fauna (ungulados e ictiofauna). La columna derecha muestra, en orden decreciente, la probabilidad de que las co-ocurrencias de los 2 criterios (fauna y arpones) no sean debidas únicamente a las fluctuaciones de la muestra.

En síntesis, los resultados obtenidos en el análisis microscópico corroboran el interés de incorporarlo al estudio de los arpones magdalenienses. Aquí hemos trabajado con una muestra limitada, pero solo en la región cantábrica son más de doscientas las piezas conservadas, por lo que su aplicación resulta prometedora. La diversidad de la evidencia etnográfica y la, de momento, poco concluyente información arqueozoológica aconsejan insistir en el estudio de los propios arpones y, al tiempo, desarrollar protocolos experimentales que nos permitan precisar el uso de los magdalenienses. El interrogante planteado por las fracturas planas identificadas en el núm. 1 es un buen ejemplo del interés del estudio experimental. Dicho análisis deberá atender a los rastros de uso producto del contacto entre armas y presas o de la interacción entre la base de las puntas y los materiales empleados para enmangarlas. Pero, además, deberá considerar los contextos sedimentarios en los que pudieron emplearse los arpones, dada su importante influencia en la formación de rastros superficiales. De hecho, la primera experimentación en este sentido, llevada a cabo por uno de nosotros (I. C.) en la orilla del río Dubna ( $\mathrm{Ru}-$ sia), con una sedimentación de granulometría muy 
fina y sin piedras, ha verificado el uso de varios arpones del yacimiento Zamostje 2 (Rusia), con niveles mesolíticos y neolíticos. Las piezas estudiadas, de apariencia 'muy fresca' y sin fractura de impacto alguna, incluyen micro-rastros producto de su contacto, en sucesivos lanzamientos fallidos, con un medio sedimentario como el descrito (Fig. 6) (Clemente et al. e. p.).

\section{AGRADECIMIENTOS}

Pablo Arias Cabal (Universidad de Cantabria), César González Sainz (Universidad de Cantabria), Marco de la Rasilla Vives (Universidad de Oviedo), Lawrence G. Straus (University of New Mexico) y Ana Belén Marín (Universidad de Cantabria) nos aportaron información y Georges Sauvet (CREAP-TRACES UMR 5608) valiosos comentarios en el análisis estadístico. Los evaluadores del manuscrito lo mejoraron con sus críticas y matizaciones. La excavación de El Horno fue
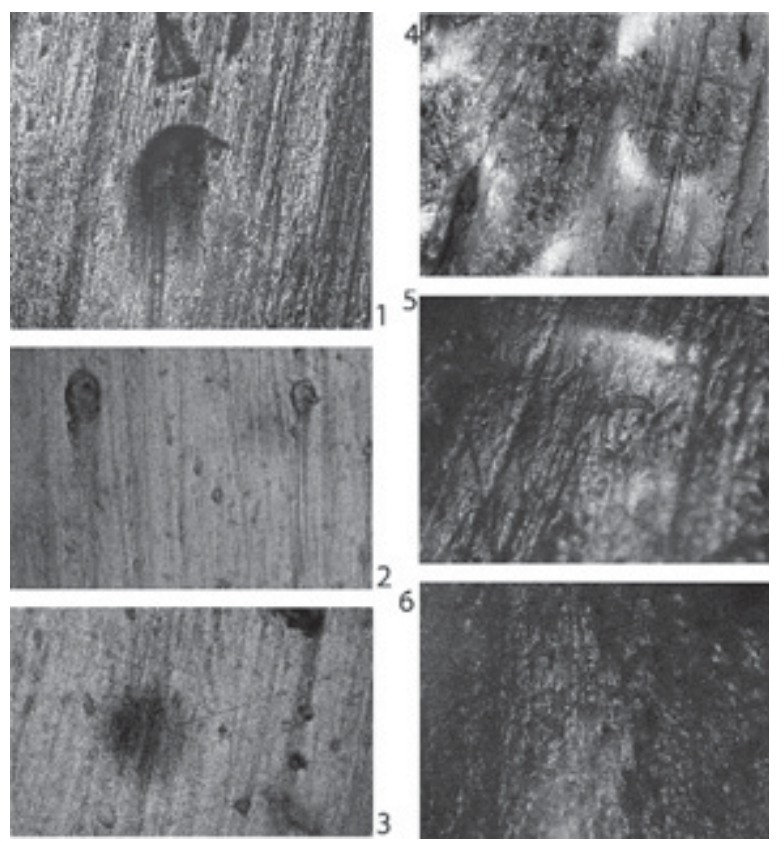

Fig. 6. Rastros experimentales en puntas de hueso: 1. tras 800 lanzamientos; 2. tras 1000 lanzamientos; 3. tras 300 lanzamientos. Imágenes 4 a 6: rastros en arpones arqueológicos de Zamostje 2 (Rusia). Todas las fotos tomadas a $100 \mathrm{X}$. financiada por el Gobierno de Cantabria y por el Proyecto Mirón.

\section{ANEXO I}

En un corpus de efectivo global n1, llamamos p1 a la fracción representada por la clase I y llamamos p2 a la proporción de un atributo dado (del cual el número total de ocurrencias en $\mathrm{n} 2$ ) en la misma clase I. Calculamos la proporción común:

$$
p=\frac{n 1 p 1+n 2 p 2}{n 1+n 2}
$$

y la desviación reducida $\varepsilon$ :

$$
\varepsilon=\frac{p 1-p 2}{\sqrt{p(1-p)\left(\frac{1}{n 1}+\frac{1}{n 2}\right)}}
$$

Podemos leer en una tabla de las desviaciones reducidas (Z-score) la probabilidad de que el valor $\varepsilon$ se vea desbordado si el intervalo entre p1 y p 2 se debe únicamente a las fluctuaciones de la muestra analizada (hipótesis de distribución normal). Solamente pueden ser retenidos aquellos casos donde esta probabilidad es inferior a 0,10 (es, decir, una probabilidad de $>90 \%$ de que la diferencia entre p1 y p2 sea significativa) (Chenorkian 1996).

\section{BIBLIOGRAFÍA}

Adán Álvarez, G. E. 1997: De la caza al útil: La industria ósea del Tardiglaciar en Asturias. Principado de Asturias. Oviedo.

Altuna, J. y Mariezkurrena, K. 1982: "Restos óseos en el yacimiento prehistórico de Abauntz (Arraiz, Navarra)". Trabajos de Arqueología Navarra 3: 347353.

Altuna, J. y Mariezkurrena, K. 1985: "Bases de subsistencia de los pobladores de Erralla: macromamíferos". Munibe 37: 87-117.

Altuna, J. y Mariezkurrena, K. 2001: "Restos de macromamíferos del yacimiento de Zatoya (Navarra)". Trabajos de Arqueología Navarra 15: 101-113.

Altuna, J. y Merino, J. M. 1984: El yacimiento prehistórico de la cueva de Ekain (Deba, Guipúzcoa). Eusko Ikaskuntza 1. San Sebastián. 
Arias, P.; Ontañón, R.; Álvarez-Fernández, E.; Cueto, M.; Elorza, M.; García-Moncó, C; Piñeiro, A.; Güth, M.; Iriarte, M. J.; Teira, L. C. y Zurro, D. 2011: "Magdalenian floors in the Lower Gallery of La Garma. A preliminary approach". En S. GaudzinskiWindheuser, O. Jöris, M. Sensburg, M. Street y E. Turner (eds.): Site-internal spatial organization of hunter-gatherer societies: Case studies from the European Palaeolithic and Mesolithic (Session C58, $15^{\text {th }}$ UISSPP Lisbon 2006). Verlag des Römisch Germanischen Central Museums. Mainz: 31-51.

Arias, P. y Pérez, C. 1995: "Excavaciones arqueológicas en Arangas, Cabrales (1991-94): Las Cuevas de Los Canes el Tiu Llines y Arangas". Excavaciones arqueológicas en Asturias 1991-94 3: 79-92.

Barandiarán, I. 1967: El Paleomesolítico del Pirineo Occidental. Universidad de Zaragoza. Zaragoza.

Barandiarán, I. 1973: Arte Mueble del Paleolítico cantábrico. Monografías arqueológicas XIV, Universidad de Zaragoza. Zaragoza.

Barandiarán, I. y Cava, A. 2001: “El Paleolítico superior de la cueva de Zatoya (Navarra): actualización de los datos en 1997". Trabajos de Arqueología Navarra 15: 5-99.

Barandiarán, J. M. 1960: Excavaciones en Atxeta. Forua (1959). Servicio de Investigaciones Arqueológicas de la Diputación Provincial de Vizcaya. Bilbao.

Bernaldo de Quirós, F.; Gutiérrez, C.; Heras, C.; Lagüera, M.; Pelayo, M.; Pumarejo, P. Y Uzquiano, P. 1992: "Nouvelles donnés sur la transition Magdalénien Supérieur-Azilien. La grotte de La Pila (Cantabria, Espagne)". En J. Ph. Rigaud, H. Laville y B. Vandermeersch (eds.): Le Peuplement Magdalénien. Paléogéographie physique et Humaine. Actes du colloque de Chancelade 1988. Ed. Comité des Travaux Historiques et Scientifiques. París: 259-269.

Breuil, H. 1912: "Les subdivisions du Paléolithique Supérieur et leur signification". Congrès International d'Anthropologie et d'Archéologie Préhistorique (compte-rendu de la 14 $4^{\text {ème }}$ session Gèneve 1912) I: 165-238. Paris.

Buc, N. y Loponte, D. 2007: "Bone tool types and microwear patterns: Some examples from the Pampa region, South America". En C. Gates St-Pierre y R. B. Walker (eds.): Bones as Tools: Current Methods and Interpretations in Worked Bone Studies. British Archaeological Reports, International Series 1622. Oxford: 143-157.

Cacho, C.; Jordá, J.; de la Torre, I. e Yravedra, J. 2001: "El Tossal de la Roca (Alicante). Nuevos datos sobre el Magdaleniense Mediterráneo de la Península Ibérica". Trabajos de Prehistoria 58 (1): 71-93.

Cacho, C. y Torre, I. de la 2005: "Les harpons magdaléniens sur le versant méditerranéen espagnol". En V. Dujardin (ed.): Industries osseuses et parures du Solutréen au Magdalénien en Europe. Table ronde sur le Paléolithique supérieur récent (Angou- lême 2003). Mémoires de la Société Préhistorique Française 39. Paris: 257-266.

Campana, D. V. 1989: Natufian and protoneolithic bone tools. The manufacture and use of bone implements in the Zagros and the Levant. British Archaeological Reports, International Series 494. Oxford.

Castaños, P. M. 1982: "Estudio de los macromamíferos del yacimiento prehistórico de Cueto de la Mina (Asturias)". Boletín del Instituto de Estudios Asturianos 105-106: 43-85.

Castaños, P. 1994: "Estudio de los macromamíferos de Laminak II". Kobie 21: 173-187.

Chenorkian, P. 1996: Pratique archéologique, statistique et graphique. Errance et Adam. Paris.

Chollet, A. y Dujardin, V. (eds.) 2005: La grotte de BoisRagot à Gouex (Vienne). Magdalénien et Azilien. Essais sur les hommes et leur environnement. Mémoire XXXVIII Société Préhistorique Française. Paris.

Clark, G. A. 1972: "Excavaciones en la cueva de Coberizas (Asturias, España)". Noticiario Arqueológico Hispanico 2: 10-37.

Clemente, I. y Gyria, E. Y. 2003: "Analiz orudi iz rever losia so stoianki Zamostje 2 (7 sloi, raskopki 19967gg.". Arjeologicheskie Vesti 10: 47-59.

Clemente, I; Gyria, E. Y.; Lozovsca, O. V. y Lozovski, V. M. 2002: "Análisis de instrumentos en costilla de alce, mandíbulas de castor y caparazón de tortuga de Zamostje 2 (Rusia)". En I. Clemente, J. F. Gibaja y R. Risch (eds.): Análisis Funcional: su aplicación al estudio de sociedades prehistóricas. British Archaeological Reports, International Series 1073. Oxford: 187-196.

Clemente, I; Maigrot, Y.; Gyria, E. Y. y Lozovsca, O. V. en prensa: "Aperos para pesca e instrumentos para el procesado de pescado en Zamostje 2 (Rusia): una experimentación para reconocer los rastros de uso". En 3er Congreso Internacional de Arqueología Experimental (Banyoles, Girona 2011).

Cleyet-Merle, J. J. 1990: La Préhistoire de la pêche. Errance. Paris.

Corchón, M. ${ }^{\text {a }}$ S. 2007: "Investigaciones en la Cueva de Las Caldas. V. Los niveles del Magdaleniense superior". Excavaciones Arqueológicas en Asturias 1999-2002 5: 47-61.

Corchón, M. ${ }^{\text {a }}$ S.; Mateos, A.; Álvarez, E.; Martínez, J.; Rivero, O. 2005: "El final del Magdaleniense Medio y la transición al Superior en el valle medio del Nalón (Asturias, España)". En N. Ferreira Bicho (ed.): O Paleolítico. Actas do IV Congresso de Arqueologia Peninsular (Faro 2004): 77-107. Faro.

Corchón, M. ${ }^{\text {a }}$ S.; Mateos, A.; Álvarez, E., Delclòs, X.; Peñalver, E. y Van Der Made, J. 2008: "Ressources complémentaires et mobilité dans le Magdalénien Cantabrique (14000-13000 BP). Nouvelles donnes sur cétacés, phoques, mollusques, ambre et jais de la Grotte de Las Caldas (Asturies, Nord de l'Espagne)". L'Anthropologie 112: 284-327. 
Costamagno, S. y Fano, M. A. 2005: "Pratiques cynégétiques et exploitation des ressources animales dans les niveaux du Magdalénien supérieur-final de El Horno (Ramales, Cantabrie, Espagne)". Paléo 17: 31-55.

Cravinho, S. y Desse-Berset, N. 2005. "Les poisons du Bois-Ragot (Gouex, Vienne)". En A. Chollet y V. Dujardin (eds.): La grotte de Bois-Ragot à Gouex (Vienne). Magdalénien et Azilien. Essais sur les hommes et leur environnement. Mémoire XXXVIII Société Préhistorique Française. Paris: 355-371.

Dockall, J. E. 1997: "Wear Traces and Projectile Impact: A Review of the Experimental and Archaeological Evidence". Journal of Field Archaeology 24: 321-331.

Estévez, J. y Vila, A. 2013: "Analysis of Palaeolithic barbed points from the Mediterranean coast of the Iberian Peninsula: an ethnoarchaeological approach". En A. Pastoors y B. Auffermann (eds.): Pleistocene foragers on the Iberian Peninsula: their culture and environment. Festschrift in honour of Gerd-Christian Weniger for his sixtieth birthday. Wissenschaftliche Schriften des Neanderthal Museums 7. Mettmann: 283-307.

Fano, M. A. 2005: "El final del Magdaleniense en la cuenca del río Asón. Nuevos datos procedentes de la Cueva de El Horno (Ramales de la Victoria, Cantabria)". En N. F. Bicho (ed.): O Paleolítico. Actas do IV Congresso de Arqueologia Peninsular (Faro 2004): 109-122. Faro.

Fano, M. A. 2008: "La Prehistoria del Valle del Asón. Excavaciones en la cueva de El Horno (Ramales de la Victoria), 2000-2001". En R. Ontañón (ed.): Actuaciones Arqueológicas en Cantabria 2000-2003. Gobierno de Cantabria. Santander: 73-77.

Fano, M. A.; d'Errico, F. y Vanhaeren, M. 2005: "Magdalenian bone industry from El Horno Cave (Ramales, Cantabria, Spain)". En V. Dujardin (ed.): Industries osseuses et parures du Solutréen au Magdalénien en Europe (Table ronde sur le Paléolithique supérieur récent, Angoulême 2003). Mémoires de la Société Préhistorique Française 39. Paris: 177-196.

Fischer, A.; Hansen, P.V. y Ramussen, P. 1984: "Macro and Micro Wear Traces on Lithic Projectile Points. Experimental Results and Prehistoric Examples". Journal of Danish Archaeology 3: 19-46.

Fortea, J.; Rasilla, M. y Rodríguez, V. 1995: “La Cueva de Llonín (Llonín, Peñamellera Alta). Campañas de 1991 a 1994". Excavaciones Arqueológicas en Asturias 1991-94 3, Gobierno del Principado de Asturias. Oviedo: 33-43.

García Gelabert, M. P. y Talavera, J. 2004: La cueva de El Valle, Rasines, Cantabria, España. British Archaeological Reports, Internacional Series 1252. Oxford.

González Echegaray, J. y Barandiarán, I. 1981: El Paleolítico Superior de la cueva del Rascaño (Santander). Centro de Investigación y Museo de Altamira monografía 3. Santander.
González Echegaray, J.; García Guinea, M. A.; Bejines, A. y Madariaga, B. 1963: Cueva de La Chora (Santander). Excavaciones Arqueológicas en España 26, Ministerio de Educación. Madrid.

González Morales, M. R. 1982: El Asturiense y otras culturas locales. La explotación de las áreas litorales de la región cantábrica en los tiempos epipaleoliticos. Centro de Investigación y Museo de Altamira monografia 7, Ministerio de Cultura. Madrid.

González Sainz, C. 1989. El Magdaleniense superiorfinal de la región cantábrica. Tantín y Universidad de Cantabria. Santander.

González Sainz, C. y González Urquijo, J. E. 2007: “El Magdaleniense reciente en la Región Cantábrica". En M. A. Fano (coord.): Las Sociedades del Paleolítico en la Región Cantábrica. Anejo 8 de la revista Kobie (2004). Diputación Foral de Bizkaia. Bilbao: 275-308.

Jordá, F. y Gómez Fuentes, A. 1982: Cova Rosa A. Departamento. de Prehistoria y Arqueología, Universidad de Salamanca. Salamanca.

Julien, M. 1982: Les Harpons Magdaléniens. XVII supplément à Gallia Préhistoire. CNRS. Paris.

Julien, M. 1995: "Harpons magdaléniens". En H. Camps-Fabrer (ed.): Fiches typologiques d'industrie osseuse préhistorique, Cahier VII: Eléments barbelés et apparentés. Ed. du CEDARC. Treignes: 13-28.

Julien, M. 1999: "Una tendance créatrice au Magdalénien: a propos des stries d'adherénce surquelques harpons". En Préhistoire d'os. Recueil d'études sur l'industrie osseuse préhistorique offer en hommage à Henriette Camps-Fabrer. Publications de l'Université de Provence: 133-142.

Julien, M. y Orliac, M. 2003: "Les harpons et les éléments barbelés". En J. Clottes y H. Delporte (ed.): La Grotte de La Vache (Ariège). Fouilles Romain Robert. I- Les occupations du Magdalénien. Éditions de la Réunion des musées nationaux et du Comité des travaux historiques et scientifiques. Paris: 221-274.

Klein, R. 1999: The human career. The University of Chicago Press. Chicago.

Le Gall, O. 2003: "Des magdaleniens et ... des poisons". En S. Costamagno y V. Laroulandie (eds.): Mode de vie au Magdalénien: apports de l'Archéozoologie. British Archaeological Reports, International Series 1144. Oxford: 119-128.

LeMoine, G. M. 1997: Use Wear Analysis on Bone and Antler Tools of the Mackenzie Inuit. British Archaeological Reports, International Series 679. Oxford.

Maigrot, Y. 2003. Etude technologique et fonctionnelle de l'outillage en matières dures animales: La station 4 de Chalain (Néolithique final, Jura, France). Thèse de Doctorat. Université de Paris I. Paris (microficha).

Marín, A. B. 2009: "Explotaition of the montagne zone of cantabrian Spain during the Late Glacial. Faunal evidence from El Mirón cave". Journal of Archaeological Research 65 (1): 69-102.

Trab. Prehist., 70, N. ${ }^{\circ}$ 2, julio-diciembre 2013, pp. 332-345, ISSN: 0082-5638

doi: $10.3989 /$ tp.2013.12116 
Marín, A. B. 2010: Arqueozoología en el Cantábrico Oriental durante la transición Pleistoceno/Holoceno. La cueva del Mirón. Ediciones Universidad de Cantabria. Santander.

Marín, A. B. y González Morales, M. R. 2007: “La Fragua cave, a seasonal hunting camp in the Lower Asón Valley (Cantabria, Spain) at the Pleistocene-Holocene transition". Anthropozoologica 41 (1): 61-84.

McBrearty, S. y Brooks, A. 2000: "The revolution that wasn't: a new interpretation of the origin of modern human behavior". Journal of Human Evolution 39: 453-563.

Múgica, J. A. 1983: "Industria ósea en la prehistoria de Guipúzcoa". Munibe 35: 451-631.

Palomo, A. y Gibaja, J. F. 2003: "Anàlisi tecnomorfològica/funcional i experimental de les puntes de fletxa". La Costa de Can Martorell (Dosrius, El Marcéeme). Mort i violencia en una comunitat del litoral català durant el tercer mil.leni A.C. Laietana 14: 179- 214.

Pétillon, J. M. 2006: Des Magdaléniens en armes. Technologie des armatures de projectile en bois de Cervidé du Magdalénien superieur de la grotte d'Isturitz (Pyrénées-Atlantiques). Artefacts 10, Éditions du Centre d'études et de documentation archéologiques (Cedarc). Treignes.

Pétillon, J. M. 2008a: "What are these barbs for? Preliminary study on the function of the Upper Magdalenian barbed weapon tips". En J. M. Pétillon, M. H. Dias-Meirinho, P. Cattelain, M. Honegger, Ch. Normand y N.Valdeyron (eds.): Projectile weapon elements from the Upper Palaeolithic to the Neolithic. Proceedings of session C83, XVth World Congress UISPP (Lisbon 2006). Palethnologie 1: 66-97.

Pétillon, J. M. 2008b: "First evidence of a whale-bone industry in the western European Upper-Paleolithic: Magdalenian artifacts from Isturitz (Pyrénées-Atlantiques, France)". Journal of Human Evolution 54: $720-726$.

Pokines, J. y Krupa, M. 1997: "Self-barbed antler spearpoints and evidence of fishing in the late Upper Paleolithic of Cantabrian Spain”. En H. Knecht (ed.): Projectile technology. Plenum Press. New York y London: 241-262.

Román, D. y Villaverde, V. 2011: "Los arpones del Magdaleniense superior mediterráneo.Valoración tipológica y cronoestratigráfica a partir de nuevas piezas halladas en la cova de Les Cendres (Teulada-Moraira, País Valenciano)". Zephyrus LXVII (enero-junio): 27-43.

Roselló, E.; Morales, A. y Cañas, J. M. 1994: “Los peces de Laminak II (Berriatua, Bizkaia)". Kobie 21: 203-219.
Semenov, S. A. 1964: Prehistoric Technology. Cory, Adams and Mackay. London.

Stodiek, U. 2000: "Preliminary results of an experimental investigation of Magdalenian antler points". En C. Bellier, P. Cattelain y M. Otte (eds.): La chasse dans la Préhistoire. Colloque international de Treignes 1990. Anthropologie et Préhistoire 111: 70-78.

Straus, L. G. y Clark, G. A., 1986: La Riera cave. Stone age hunter-gatherer adaptations in Northern Spain. Anthropological Research Papers 36, Arizona State University. Tempe.

Straus, L. G. y González Morales, M. R. 2003: “El Mirón cave and the 14C chronology of Cantabrian Spain". Radiocarbon 45 (1): 41-58.

Villaverde, V. y Román, D. 2005/2006: “Los arpones del Magdaleniense superior de la Cova de les Cendres y su valoración en el contexto del Magdaleniense mediterráneo". Homenaje a J. Altuna. Munibe 57 (2): 207-225.

Weniger, G. C. 1992: "Function and form: an ethnoarchaeological analysis of barbed points from northern hunter-gatherers". En F. Audouze (ed.): Ethnoarchéologie: justification Problèmes, limites. Actes des XIIe rencontres internationales d'archéologie et d'histoire d'Antibes 1991. Editions APDCA. Juanles-Pins: 257-268.

Weniger, G. C. 1995: Widerhakenspitzen des Magdalénien Westeuropas. Ein Vergleich mit ethnohistorischen Jägergruppen Nordamerikas. Madrider Beiträge 20, Philipp von Zabern. Mainz-am-Rhein.

Weniger, G. C. 2000: "Magdalenian barbed points: harpoons, spears and arrowheads". En C. Bellier, P. Cattelain y M. Otte (eds.): La chasse dans la Préhistoire. Colloque international de Treignes 1990. Anthropologie et Préhistoire 111: 79-87.

Weninger, B.; Jöris, O. y Danzeglocke, U. 2007: CalPal-University of Cologne Radiocarbon Calibration Program Package CalPal2007_HULU. Institut der Ur-und Frühgeschichte, Universität zu Köln. Köln http://www.calpal.de (consulta 12/01/2011).

Yellen, J. E.; Brooks, A. S.; Cornelissen, E.; Mehlman, M. J. y Stewart, K. 1995: "A Middle Stone Age worked bone industry from Katanda, Upper Semliki Valley, Zaire". Science 268: 553-556.

Yravedra Sainz de los Terreros, J. 2002: "Especialización o Diversificación. Una nueva propuesta para el Solutrense y el Magdaleniense Cantábrico". Munibe 54: 3-20.

Yravedra Sainz de los Terreros, J. 2010: “Zooarqueología y tafonomía del yacimiento de Hornos de la Peña (San Felices de Buelna, Cantabria)". Complutum 21 (1): 69-86. 


\section{FE DE ERRATAS TRABAJOS DE PREHISTORIA 70, 2013}

Fano, M.A.; Clemente, I. y Rivero, O. 2013: “Apuntes en torno al uso de los arpones magdalenienses: primeras observaciones microscópicas a partir de los materiales de El Horno (Ramales de la Victoria, Cantabria)". Trabajos de Prehistoria 70 (2): 332-345. doi: $10.3989 /$ tp .2013 .12116

En el encabezamiento de las páginas impares figura entorno en lugar de en torno.

La tabla.1 que se muestra a continuación y su pie sustituyen a la tabla. 1 y su pie de las pp. 339-340 .

\begin{tabular}{|c|c|c|c|c|c|c|c|c|c|c|c|c|c|c|c|c|c|c|c|}
\hline \multirow[b]{2}{*}{ Yacimiento } & \multirow[b]{2}{*}{ Etapa } & \multicolumn{3}{|c|}{ Cervus } & \multirow{2}{*}{$\begin{array}{c}\text { Bos } \\
E\end{array}$} & \multicolumn{2}{|c|}{ Equus } & \multicolumn{3}{|c|}{ Capra } & \multicolumn{2}{|c|}{$\begin{array}{l}\text { Rupica- } \\
\text { pra }\end{array}$} & \multicolumn{2}{|c|}{$\begin{array}{l}\text { Capreo- } \\
\text { lus }\end{array}$} & \multirow{2}{*}{\begin{tabular}{c|}
$\begin{array}{c}\text { Ran- } \\
\text { gifer }\end{array}$ \\
$\mathrm{E}$
\end{tabular}} & \multirow{2}{*}{$\begin{array}{c}\text { Sus } \\
\mathrm{E}\end{array}$} & \multicolumn{2}{|c|}{$\begin{array}{l}\text { Ictiofau- } \\
\text { na fluvial }\end{array}$} & \multirow{2}{*}{$\begin{array}{c}\begin{array}{c}\text { Ictio- } \\
\text { fauna } \\
\text { marina }\end{array} \\
E\end{array}$} \\
\hline & & MF & FM & E & & FM & E & MF & FM & E & $\mathrm{FM}$ & $\mathrm{E}$ & FM & E & & & $\mathrm{F}$ & E & \\
\hline La Paloma 6 (1) & MM & - & & & - & & - & & & - & & - & & - & ! & & & & \\
\hline La Paloma 4 (2) & MSF & - & & & - & & - & & & - & & ! & & & & & & - & \\
\hline Sofoxó (3) & MSF & & $\square$ & & - & & - & & - & & & - & & - & & - & & $\square$ & \\
\hline Las Caldas V (4) & MM & & - & & & & - & & - & & - & & - & & & & & - & \\
\hline Las Caldas IV (5) & MM & & $\square$ & & - & & ! & & - & & ! & & & $\square$ & & & & $\square$ & \\
\hline Las Caldas III (6) & MM-MSF & & - & & & & - & & - & & - & & & & & & & $\square$ & - \\
\hline Las Caldas II (7) & MSF & & & - & & & - & & & - & - & & & $\square$ & & & & & \\
\hline Cova Rosa A (8) & MSF & & & - & & & & & & - & & & & & & & & & \\
\hline Tito Bustillo 1a (9) & M & - & & & - & & - & & & - & & - & & - & & & & - & \\
\hline Tito Bustillo $1 \mathrm{~b}(10)$ & M & - & & & - & & - & & & - & & - & & & - & & - & & - \\
\hline Tito Bustillo 1c (11) & M & - & & & - & & - & & & - & & - & & & & & & - & \\
\hline Tito Bustillo 2 (12) & M & - & & & & & & & & - & & - & & & & & & & \\
\hline Coberizas (13) & MI & & & - & & & & & & - & & ! & & & & & & - & \\
\hline Cueto de la Mina B (14) & MSF & & - & & - & & - & & - & & & - & & - & घ & & & & \\
\hline La Riera 18 (15) & MI & - & & & & & - & & - & & & & & & & & & & \\
\hline La Riera 19 (16) & MI & - & & & & & - & & - & & & $\square$ & & - & & & & - & \\
\hline La Riera 20 (17) & MI-MM & - & & & & & - & & - & & & & & - & & & & & \\
\hline
\end{tabular}




\begin{tabular}{|c|c|c|c|c|c|c|c|c|c|c|c|c|c|c|c|c|c|c|}
\hline \multirow[b]{2}{*}{ La Riera 21-23 (18) } & \multirow[b]{2}{*}{ MSF } & \multicolumn{3}{|c|}{ Cervus } & \multirow[t]{2}{*}{ Bos } & \multicolumn{2}{|c|}{ Equus } & \multicolumn{3}{|c|}{ Capra } & \multicolumn{2}{|c|}{$\begin{array}{c}\text { Rupica- } \\
\text { pra }\end{array}$} & $\begin{array}{l}\text { Capreo- } \\
\quad \text { lus }\end{array}$ & \multirow{2}{*}{$\begin{array}{c}\text { Ran- } \\
\text { gifer }\end{array}$} & \multirow{2}{*}{$\begin{array}{c}\text { Sus } \\
\square\end{array}$} & \multicolumn{2}{|c|}{$\begin{array}{l}\text { Ictiofau- } \\
\text { na fluvial }\end{array}$} & \multirow[t]{2}{*}{$\begin{array}{c}\text { Ictio- } \\
\text { fauna } \\
\text { marina }\end{array}$} \\
\hline & & - & & & & & - & & & a & & & - & & & & & \\
\hline La Riera 24 (19) & MSF & & ! & & & & ! & & ! & & & ! & ! & - & & & - & \\
\hline La Riera 25 (20) & MSF-AZ & & ! & & & & & & & $\square$ & & & ! & & & & ! & \\
\hline La Riera 26 (21) & MSF-AZ & & ! & & & & - & & ! & & & - & - & & - & & ! & - \\
\hline Los Canes 2c (22) & MSF & & & ! & & & & & ! & & & ! & & & & & & \\
\hline Hornos de la Peña (23) & $\mathrm{M}$ & & ! & & - & ! & & & & ! & ! & & & & & & & \\
\hline El Pendo II (24) & MSF & ! & & & ! & & ! & & & ! & & ! & ! & & ! & & & \\
\hline Morín 2 (25) & MSF & ! & & & ! & & ! & & & ! & & ! & ! & - & - & & & \\
\hline El Rascaño 4b (26) & MI & & & ! & & & ! & ! & & & & & & & & & & \\
\hline El Rascaño 4a (27) & MI & & & $\square$ & - & & ! & - & & & & & & & & & & \\
\hline El Rascaño 3 (28) & MI & & & - & ! & & - & - & & & & - & & & & & - & \\
\hline El Rascaño 2.3 (29) & MSF & & & ! & & & ! & ! & & & & ! & & & ! & & - & \\
\hline El Piélago 6 (30) & MSF & & & ! & & & & & ! & & & ! & & & & & & \\
\hline El Piélago 5b (31) & MSF & & & - & & & & & ! & & & ! & & & & & & \\
\hline El Piélago 5a (32) & MSF & & & ! & & & & & ! & & ! & & & & & & & \\
\hline La Garma L3 (33) & MM & & - & & & - & & & & - & & & - & - & & & - & \\
\hline La Garma Gal. Inf. (34) & MM & & & - & - & - & & & & & & & & - & & & & \\
\hline El Valle (35) & MSF & - & & & & & & & ! & & & ! & - & & & & - & \\
\hline El Mirón 12 (36) & MSF & & ! & & & & " & & ! & & & & - & & & & & \\
\hline El Mirón 308 (37) & MSF & & ! & & & & & & ! & & & ! & & & & & & \\
\hline El Mirón 307 (38) & MSF & & ! & & & & & & ! & & & ! & - & & ! & & & \\
\hline El Mirón 106 (39) & MSF & & 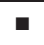 & & & & ! & & ! & & & ! & - & & - & & & \\
\hline El Mirón 105 (40) & MSF & & ! & & & & & & ! & & & & & & & & & \\
\hline El Mirón 104 (41) & MSF & & ! & & & & ! & & ! & & & ! & & & & & & \\
\hline El Mirón 103 (42) & MSF & & & - & & & & & & - & & & & & & & & \\
\hline El Horno 3 (43) & MSF & & & & & & & & & ! & & & & & & & ! & \\
\hline El Horno 2 (44) & MSF & & & - & & & ! & ! & & & & ! & - & & $\square$ & $\square$ & & \\
\hline El Horno $1(45)$ & MSF & & & - & & & ! & ! & & & & - & & & & - & & \\
\hline La Fragua (46) & MSF & & ! & & ! & & & & ! & & & ! & $\square$ & & ! & & & \\
\hline Atxeta E (47) & MSF & - & & & & & - & & & - & & & & & & & & \\
\hline Santimamiñe VI (48) & MSF & & ! & & ! & & ! & & & - & & ! & ! & - & ! & & ! & \\
\hline Lezetxiki I (49) & MSF & & & ! & ! & & ! & & & ! & & ! & & & - & & & \\
\hline Laminak II (50) & MSF & & ! & & - & & ! & & & ! & & ! & & & ! & - & & - \\
\hline Ermittia (51) & $\mathrm{M}$ & & & ! & ! & & ! & ! & & & & ! & $\square$ & - & ! & & - & \\
\hline Urtiaga F (52) & MI & & & - & - & & - & & & - & & - & $\square$ & - & & & & \\
\hline Urtiaga D (53) & MSF & & " & & $\square$ & & I & & - & & & ! & a & - & $\square$ & & - & \\
\hline Ekain VII (54) & MI & - & & & - & & ! & & & ! & & ! & - & & & & - & \\
\hline Ekain VIb (55) & MSF & & - & & - & & & & - & & & & - & - & & & ! & \\
\hline Ekain VIa (56) & MSF & & & I & घ & & & & ! & & & ! & - & & & & ! & \\
\hline Ekain V (57) & MSF-AZ & & ! & & - & & & & - & & & - & - & & & & ! & \\
\hline Erralla V (58) & MI & & & 口 & - & & ! & - & & & & ! & - & - & & & ! & \\
\hline Erralla III-II (59) & MSF & & & - & - & & - & & ! & & ! & & - & - & & & ! & \\
\hline
\end{tabular}




\begin{tabular}{|c|c|c|c|c|c|c|c|c|c|c|c|c|c|}
\hline \multirow[b]{2}{*}{ Aitzbitarte IV (60) } & \multirow[b]{2}{*}{ MSF } & \multicolumn{2}{|c|}{ Cervus } & \multirow{2}{*}{$\begin{array}{c}\text { Bos } \\
\end{array}$} & Equus & Capra & \multicolumn{2}{|c|}{$\begin{array}{c}\text { Rupica- } \\
\text { pra }\end{array}$} & $\begin{array}{l}\text { Capreo- } \\
\text { lus }\end{array}$ & \multirow{2}{*}{$\begin{array}{c}\text { Ran- } \\
\text { gifer }\end{array}$} & \multirow{2}{*}{$\begin{array}{l}\text { Sus } \\
\square\end{array}$} & $\begin{array}{l}\text { Ictiofau- } \\
\text { na fluvial }\end{array}$ & \multirow[t]{2}{*}{$\begin{array}{c}\text { Ictio- } \\
\text { fauna } \\
\text { marina }\end{array}$} \\
\hline & & - & & & - & - & $\square$ & & - & & & & \\
\hline Abauntz e (61) & MM & & - & - & - & - & $\square$ & & & - & & ! & \\
\hline Zatoya IIb (62) & MSF & - & & - & - & - & & - & & घ & - & - & \\
\hline Zatoya II (63) & MSF & - & & ! & ! & ! & & - & - & & ! & & \\
\hline
\end{tabular}

Tab. 1. Muestra de 63 niveles del Magdaleniense (M) Cantábrico con y sin arpones, y estimación de la fauna. Se indican, mediante sombreado, los niveles con arpones. Ungulados (Número de Restos $>30$ ): MF muy frecuente $>80 \%$; FM frecuencia media 20 a $80 \%$; E escaso $<20 \%$. Ictiofauna (no porcentual): E escaso; F frecuente. Atribución cronocultural: MI M Inferior; MM M Medio; MSF M Superior-Final; AZ Aziliense. Bibliografía: (1) Adán 1997. (2) González Sainz 1989; Adán 1997. (3) Adán 1997. (4-5) Corchón et al. 2005. (6) Corchón et al . 2005; Corchón et al. 2008. (7) Corchón 2007. (8) Jordá y Gómez Fuentes 1982. (9-11) González Sainz 1989. (12) Yravedra 2002 . (13) Clark 1972; González Morales 1982. (14) Castaños 1982; González Sainz 1989. (15-21) Straus y Clark 1986. (22) Arias y Pérez 1995; Adán 1997. (23) Yravedra 2010. (24-25) González Sainz 1989. (26-29) González Echegaray y Barandiarán 1981. (30-32) González Sainz 1989. (33) Fernández 2001. (34) Arias et al. 2011. (35) García Gelabert y Talavera 2004 (36) Straus y González Morales 2003. (37-42) Marín 2009, 2010. (43-45) Fano 2005; Costamagno y Fano 2005. (46) Marín y González Morales 2007. (47) Barandiarán 1960; González Sainz 1989. (48-49) González Sainz 1989. (50) Castaños 1994; Roselló et al. 1994. (51) González Sainz 1989. (52-53) Barandiarán 1967. (54-57) Altuna y Merino 1984 . (58-59) Altuna y Mariezkurrena 1985. (60) González Sainz 1989. (61) Altuna y Mariezkurrena 1982. (62-63) Altuna y Mariezkurrena 2001; Barandiarán y Cava 2001. Nota: cuando se recogió la información, no se disponía aún de los datos relativos al MI y MM de El Mirón, ni tampoco de los de la reciente revisión del depósito arqueológico de Santimamiñe . 